\title{
A música francesa reconfigurada no jazz modal de Bill Evans
}

\author{
Deborah Mawer (Lancaster University, Inglaterra) \\ d.mawer@lancaster.ac.uk \\ Tradução de Fausto Borém (UFMG, Belo Horizonte, MG) \\ fborem@ufmg.br
}

\begin{abstract}
Resumo: Embora seja senso comum que a música francesa, especialmente a do século $X X$, tenha exercido influência no estilo improvisatório do pianista de jazz norte-americano Bill Evans (1929-1980), a importância deste papel é raramente abordada em estudos bem fundamentados. Estes dois pontos - música francesa e Evans - oferecem uma oportunidade para investigar suas diversas relações musicais, desde paralelos e interseções a ecletismos específicos, os quais podem assimilar, adaptar e individualizar uma dada fonte. Implícitos aí estão os "cruzamentos" e transformações de gênero, cultura, identidade nacional e linha do tempo, assim como as questões de influência; discute-se aqui a natureza e mutabilidade dos materiais musicais. Busco mostrar a riqueza e significado destas interações em dois estudos de caso: aspectos de Kind of blue (DAVIS, 1959) e Peace Piece (EVANS, 1958), em conexão com Chopin (enquanto francês adotado), Ravel e Messiaen. Por meio dos textos de RAVEL (1928) e outros, argumento que, particularmente com o repertório francês, Evans descobriu uma afinidade e catalisador para suas prioridades de improvisação: lirismo, linhas polifônicas, uma rica paleta de $7^{\text {as }}$ e $9^{\text {as }}$, texturas requintadas, voicings e timbres - um veículo para sua expressividade e imaginação. Da mesma forma, é intrigante observar como uma música francesa relativamente velha tenha sobrevivido e se reconfigurado - como um camaleão - dentro de um novo contexto do pós-guerra.
\end{abstract}

Palavras chave: ecletismo de Bill Evans; hibridismo em música; música francesa e jazz modal jazz; transformação e improvisação musical; influência entre música erudita e popular.

\section{French Music Reconfigured in the Modal Jazz of Bill Evans}

Abstract: Although French classical music, especially that of the twentieth-century, is commonly understood to have played a role in the improvisational thinking of the American modal jazz pianist Bill Evans (1929-1980), its relevance has rarely been probed in scholarly depth. These loci - French music and Evans - appear to offer an ideal opportunity for investigating relations between musical types: from parallels, potential intersections, through to specific eclecticisms, which could assimilate, adapt and individualize a given source. Implicit are 'crossings' and transformations of genre, culture, national identity and timeframe, as well as questions of influence; at issue are the nature and mutability of music materials. I aim to show the richness and significance of these interactions in two case studies: aspects of Kind of Blue (DAVIS, 1959) and Peace Piece (EVANS, 1958), in connection with Chopin (as an adoptive Frenchman), Ravel and Messiaen. Using critical ideas of RAVEL (1928) and others, I argue that in French repertory particularly, Evans discovered an affinity with, and catalyst for, his improvisational priorities: lyricism, polyphonic lines, a rich harmonic palette of sevenths and ninths, subtle textures, voicings and exquisite tone - a vehicle for expressivity and imagination. Conversely, it is intriguing that relatively old French music has lived on, reconfigured - chameleon-like - within a new postwar context.

Keywords: eclecticism of Bill Evans; hybridism in music; French music and modal jazz; music transformation and improvisation; influence between classical and popular music.

\footnotetext{
Agradecimento: Este artigo foi gentilmente cedido pelos editors de The Jazz Chameleon: The Refereed Proceedings of the 9th Nordic Jazz Conference August 19-20, 2010, Helsinki, Finland. Edited by Janne Mäkelä (The Finnish Jazz \& Pop Archive). Helsinki: The Finnish Jazz \&t Pop Archive \&t Turku: International Institute for Popular Culture, 2011. (Disponivel como e-Book em http://iipc.utu. fi/publications.html).
} 


\section{1 - Introdução}

É senso comum que a música francesa erudita, especialmente aquela do século $X X$ influenciou 0 pensamento improvisatório de Bill Evans (1929-1980) no final da década de 1950, relação que faz parte de uma tradição mais ampla que remonta a Duke Ellington, Bix Beiderbecke e outros. Mas, ao mesmo tempo, a relevância deste repertório para Evans, músico de formação erudita, tem sido levianamente descartada e geralmente dada como "certa" e, por isso, raramente sondada em trabalhos acadêmicos de maior profundidade. Esta complacência levanta algumas questões. Por exemplo, houve influência da música russa? Que papeis a música francesa teria exercido sobre a arte de Evans? Mais particularmente, de que maneiras a música francesa poderia ser reconfigurada dentro do jazz modal?

Estes loci - música francesa e Bill Evans - oferecem uma oportunidade ideal para uma investigação detalhada sobre as relações entre tipologias musicais. Estas relações podem incluir desde paralelos e interseções em potencial até ecletismos específicos (nos quais uma causalidade pode, plausivelmente, ser estabelecida). Relações que poderiam assimilar, adaptar e individualizar fontes do tipo "camaleão". E darei nome a esse terceiro tipo de conexão, cujo potencial será discutido neste artigo: a "relação fonte-produto". Devo enfatizar que a identificação de qualquer dessas práticas ecléticas não tem uma conotação depreciativa: significa simplesmente o que um artista revela dentro de um contexto cultural, no qual estão implícitos os "cruzamentos" e transformações de gênero, cultura, identidade nacional e época. Também implícita está a questão inerente da influência musical. Uma breve alusão pode ser feita às ideias de intelectuais referenciais da literatura como Harold BLOOM (1973) e T. S. ELIOT (1951), que anteriormente sustentaram pontos de vista teóricos opostos sobre a questão da influência basicamente "ansiedade" versus "generosidade" - e que foram trazidas subsequentemente para a musicologia por Joseph STRAUS (1990). Mas não cabe aqui, em um artigo de pequeno escopo, uma discussão sobre este assunto (no meu livro no prelo French Music in Conversation with Jazz há um capitulo sobre Bill Evans e a música francesa). Atenho-me à natureza e mutabilidade dos materiais musicais; ou, às vezes, à constância de materiais dentro de um contexto alterado. Por ser especialista na música francesa, me interesso em explorar o impacto da música francesa em ambientes posteriores, especialmente no jazz. Quero apresentar um pouco da relação musical Evans-música francesa que ainda não foi explorada. Primeiro, quero checar o senso comum da associação entre Evans e a música francesa (e em qual extensão isso acontece). Segundo, quero estudar aspectos específicos em dois estudos de caso: o disco Kind of Blue (DAVIS, 1959) e a peça Peace piece (EVANS, 1958). Quero investigar estas possiveis relações musicais, embora me contendo a um espaço reduzido. Desta forma, quero trazer à tona a arte de Bill Evans.

\section{2 - Relacionando Bill Evans e a música francesa}

Na família de Evans, a presença musical de sua mãe ucraniana, e sua educação, que incluiu aulas de violino e piano, certamente significaram que ele foi exposto a uma música variada. Como observa o principal biógrafo de Evans, Peter PETTINGER (1998, p.16), isto permitiu seu acesso a "sonatas de Mozart e Beethoven e obras de Schumann, Rachmaninoff, Debussy, Ravel, Gershwin ... Villa-Lobos, Khachaturian, Milhaud e outros." Imediatamente, nossa atenção se volta para uma ampla paleta de compositores ocidentais, do Classicismo às figuras românticas austro-germânicas, chegando a uma equilibrada seleção de compositores russos e franceses do século XX. A dimensão russo-ucraniana é claramente relevante e, por isso, a conexão Evans-França não é, de forma alguma, exclusiva. Sem pretender consenso, penso que os domínios russo e francês podem ser considerados, grosso modo, como de significado semelhante. Esses "cruzamentos" se desenvolveram no estudo formal de música de Evans, que incluiu técnicas de harmonia e composição no Southeastern Louisiana College, onde se graduou em 1950.

No seu artigo The Poet: Bill Evans, Gene LEES (1997, p.421), respeitada autoridade em jazz, observou que Evans "praticava procedimentos colorísticos, voicings e nuanças de compositores pós-românticos como Debussy, Ravel, Poulenc, Scriabin e, talvez, Alban Berg". Assim, Lee enfatiza os impressionistas franceses Debussy e Ravel, ao mesmo tempo em que expande a representação neoclássica, com Poulenc e Milhaud. Também expande o domínio russo com a inclusão de um compositor influenciado pela música francesa: Scriabin. Apesar da generalização, há um consenso entre a maioria dos autores referenciais sobre Evans de que os compositores franceses eruditos, de fato, constituem uma força importante. Podemos também fundamentar essa questão recorrendo às diversas entrevistas que 0 próprio Evans concedeu. Em uma delas (GINIBRE, 1965), ele declarou: "Adoro os impressionistas. Adoro Debussy. É um dos meus compositores preferidos". Da mesma forma, no que diz respeito aos neoclássicos, como Les Six, Evans conta: "Lembro minha primeira audição da politonalidade de Milhaud e, na verdade, com uma peça que ele provavelmente não considerava grande coisa era uma peça antiga chamada Suite provençale - que abriu minha percepção para algumas coisas" (ENSTICE e RUBIN, 1992, p.136). Então, o que lhe era atraente nesta música francesa? Argumento que, particularmente no repertório francês do início do século $X X$, Evans encontrou uma afinidade deste mundo sonoro com suas próprias prioridades de improvisação: lirismo, linhas polifônicas, uma rica paleta de $7^{\text {as }}$ e $9^{\text {as }}$, texturas sutis e voicings; resumindo: um veículo para sua expressividade (cabe aqui comentar que, ao privilegiar lirismo e melodia, não estou defendendo uma exclusividade nesta relação: claramente, as melodias intricadas na mão direita de Evans também se desenvolveram, em parte e diretamente, das tradições do 
piano no jazz, especialmente de "Bud" Powell, Nat "King" Cole e Lennie Tristano). Embora melodicamente diverso e modalmente livre (traço em comum com parte da música russa), este repertório francês ainda estava baseado em tônicas. Da mesma forma pensava Evans: "Penso que toda a harmonia é como uma expansão e retorno à tônica" (LEES, 1997, p.434).

Além disso, esta contínua miscigenação aparentemente contribuiu para a sonoridade distinta de Evans ao piano. LEES (1997, p.441) reconhece que "Bill trouxe ao jazz o tipo de som familiar a Debussy e Ravel. .. som que é óbvio no mundo erudito de performers como Walter Gieseking e Emil Gilels". Mais ainda, parece que isto estimulou sua imaginação. Afinal de contas, improvisadores precisam de uma marca estilistica ou fórmulas próprias, uma vez eu qualquer noção de improvisação espontânea sem estruturas predeterminadas ou um conhecimento harmônico inerente é um mito (BERLINER, 1994, p.1). E sabemos que Evans foi "um dos improvisadores mais imaginativos, inventivos e aventureiros que esta arte já conheceu" (LEES, 1997, p.441-442).

Comparações entre Evans e Frédéric Chopin (este um antecessor do século XIX e francês por adoção) são costumeiras e úteis, como veremos abaixo, mas e entre Evans e Ravel? Em cada uma dessas comparações, o piano está no foco do ser artístico. Ravel compunha ao piano. Para Evans, "o piano, que ele podia atacar e sustentar com grande clareza, permaneceu como seu amor verdadeiro" (PETTINGER, 1998, p.11). Ambos privilegiavam a forma de miniaturas e preferiam nuanças sutis ao invés das grandes intensidades, das dinâmicas fortes. 0 foco na melodia era também ponto pacífico. Ambos eram experts nas heranças musicais que escolheram: Ravel em Couperin, Mozart e Mendelssohn; Evans em Chopin e Ravel. Ambos eram indivíduos sensíveis para quem a música oferecia uma saída emocional não verbal.

Reciprocamente, como ávidos leitores que eram, ambos valorizavam a palavra escrita: Ravel preferindo Marcel Proust, Stéphane Mallarmé e Edgar Allan Poe; Evans preferindo Thomas Hardy e William Blake. E a própria palestra Contemporary Music de Ravel, proferida por ocasião de sua turnê norte-americana na primavera de 1928, fornece um conjunto de principios que relacionam música erudita e jazz e que pode funcionar na direção oposta (jazz e música erudita) para testar a prática de Evans, como pretendo mostrar nos estudos de caso. Cada obra de arte, atrás da qual há uma fonte confiável, inicialmente "adota" parte deste material e o submete a uma "estilização imediata" - ou mesmo "manipulação", transformando-o em um novo ambiente que abarca "características nacionais" e "individualidades"(RAVEL, 1928, p.140) gerando, assim, originalidade. 0 próprio Ravel disse em outra ocasião: "Se você tem algo a dizer, esse algo nunca surgirá com mais distinção do que na infidelidade não intencional a um modelo" (MAWER, 2000, p.56). 0 que não significa, de forma alguma, uma criatividade de segunda categoria.
Para fundamentar os dois estudos de caso que apresento a seguir, aconselho o leitor a consultar as fontes relevantes de áudio e escritas (por razões de copyright, citações musicais não estão incluidas neste artigo). As fontes para o primeiro estudo de caso incluem uma gravação relançada em CD (DAVIS, 1959), sua transcrição (DAVIS, sem data) e diversas partituras de música francesa (MILHAUD, 1923; RAVEL, 1911; RAVEL, 1927; RAVEL, 1931; RAVEL, 1932). Em relação ao segundo estudo de caso, as fontes que 0 fundamentam incluem a gravação de áudio lançada em CD (EVANS, 1958), sua transcrição por Jim AIKIN (1980, p.46-49) [reproduzida após o presente artigo, às p.????? desse volume de Per Musi] e diversas partituras de música francesa (CHOPIN, sem data; JOLIVET, 2002; MESSIAEN, 1964). Quando me refiro às partituras e transcrições que utilizam letras ou números de ensaio, emprego as seguintes abreviaturas: tomemos três exemplos: Ex.1 -1 [exemplo um menos um] se refere ao compasso anterior à letra ou número de ensaio 1; Ex.1 [exemplo um] denota o compasso inteiro deste número ou letra de ensaio; e Ex. 1 +1 [exemplo um mais um] se refere ao compasso posterior à letra ou número de ensaio 1.

\section{3 - Estudo de caso N.1: Kind of Blue}

Meu primeiro estudo de caso enfatiza uma relação híbrida fonte-produto entre o Concerto para a mão esquerda de Ravel, composto em 1920-1930, que foi apresentado a Miles Davis por Evans (DAVIS \& TROUPE, 1989, p.216) e fez parte de um álbum icônico, Kind of blue (DAVIS, 1959). No seu estilo direto, Miles Davis afirmou "porque estávamos com a cabeça em Ravel (especialmente seu Concerto para a mão esquerda. . .) e Rachmaninoff. . . tudo aquilo estava no ar, em algum lugar" e "Estávamos com aquela tendência - como Ravel, tocando uns sons somente com as teclas brancas" (DAVIS \& TROUPE, 1989, p.224-225). De fato, no riff de abertura de All blues, a figura inicial no contrafagote do Concerto para a mão esquerda (RAVEL, 1931) é adotada e adaptada: temos aqui a natureza camaleônica do jazz em ação. Entretanto, esta obra de Ravel não é, estritamente, um produto do impressionismo, como percebia Evans, mas um produto neoclássico do entre guerras, estilo que foi influenciado pelo jazz mais antigo e pela música de George Gershwin.

No modo de Mi menor, RAVEL (1931, c.2-3) apresenta as notas Mi - Fá \# - Mi - Sol em ritmo pontuado, iniciando com uma anacruse de semicolcheia. Então, expande a figura ascendentemente. Por seu lado, depois do Sol inicial, o riff de Evans e Davis explora as notas Ré - Mi - Ré - Fá, o que é uma transposição do fragmento de Ravel uma $2^{\text {a }}$ menor abaixo, o que é equilibrado por uma linha descendente até o Sol grave (Ré - Mi - Ré -Sol). De fato, este último padrão também corresponde a um trecho da Sonata pra violino e piano (RAVEL, 1927) c.8-9 - do movimento "blues": Mib - Fá - Mib - Láb. Além disso, o material de Evans na introdução de quatro compassos compreende um tremolo oscilante entre as notas Sol e Lá, no qual outra conexão raveliana (desta vez, impressionista) está implícita: "Um bom número de 
suas canções começava com breves introduções etéreas, coloridas por ondulações delicadas e pontilhistas. Era uma marca de Evans, talvez pensando no pianíssimo de flautas, clarinetas e harpas do Daphnis and Chloe de Ravel" (PETTINGER, 1998, p.144).

É discutível se a similaridade do motivo do contrabaixo que inicia o sujeito da fuga em A Criação do mundo (MILHAUD, 1923) nessa relação seria ainda maior. Depois de um Ré inicial, Milhaud utiliza o mesmo fragmento melódico: Ré Mi - Ré - Fá [Ré] e, expande a ideia por meio da $3^{\text {a }}$ blues: Ré - Mi - Ré - Fá \# / Fá natural - Ré (MILHAUD, 1923, Ex.11 -1). Por sua vez, cada uma destas figuras se relaciona com The Man I love de Gershwin. Todos compartilham este motivo de quatro notas - um tipo de paradigma identificado pelo crítico veterano André HODEIR (1958, p.254) como "favorito dos compositores 'inspirados' pelo jazz". E, assim, o ciclo continua. . . quando DAVIS (1989, p.225) comenta que o modalismo das teclas brancas é a resposta para muitas coisas, enquanto que os ritmos pontuados ou swingados são traços comuns.

A dívida de Evans com Ravel é também evidente no seu longo solo em All blues, novamente recorrendo ao modalismo das teclas brancas - por volta de 8'26" da gravação (DAVIS, 1959). Sua melodia melancólica no modo Dórico em Sol (DAVIS, s.d.; veja letra D, c.1-10) guarda semelhança com o solo no primeiro movimento do Concerto para piano e orquestra em Sol de RAVEL (1932, Ex.4 +2 ), no qual sua $3^{\text {a }}$ menor expressiva, mais a $7^{\text {a }}$ abaixada, que é um gesto reminiscente da bela cantilena do Concerto para a mão esquerda (RAVEL, 1931, Ex.9 -3). 0 andamento mais rápido e a sensação de urgência em All blues são sinais de como a resposta eclética de Evans se torna "individualizada". Os blocos harmônicos de Evans na segunda inversão, com as notas Ré - Mi - Fá na linha do tenor, combinados com os ritmos longos-curtos swingados (DAVIS, s.d.; veja letra $D+1$ ), podem ser ouvidos como uma adaptação da entrada do piano no Concerto para a mão esquerda (RAVEL, 1931, Ex.4 +3), que apresenta tríades em segunda inversão combinadas com acordes de sétima em ritmos pontuados como uma variação da figura do contrafagote inicial (estes blocos de acorde de tríades em segunda inversão também ocorrem na segunda valsa das Valses nobles et sentimentales (RAVEL, 1911) a partir do c.25, no qual o andamento lento, as baixas dinâmicas e a expressividade são congruentes tanto com a própria prática de Evans quanto de sua atitude de privilegiar o impressionismo francês). Este padrão rítmico-harmônico de semelhança surpreende mais ainda, mais à frente, no solo de Evans (Davis, s.d.; veja letra $D+16$ ), no qual efetivamente "amplifica" Ravel em uma série de acordes de 9a, repetidos em figuras pontuadas: Fá - Lá - Mi - Sol, depois Sol - Si -Fá - Lá e, depois, Lá - Dó - Sol - Si.

Provendo uma ligação com o segundo estudo de caso, é sabido que uma característica fundamental de Flamenco sketches foi iniciativa do próprio Evans, e remonta a Peace piece. Os acordes alternantes de Dó com $7^{\text {a }}$ (Dó, Mi, Sol, Si) e Sol com 11a (Sol, Si, [Ré], Fá, Lá, Dó) constituem um duplo empréstimo. Primeiro, Evans revisitando sua própria obra. Segundo, esta progressão em Peace piece foi, por sua vez, tomada por empréstimo de Some other time de Leonard Bernstein. Peri Cousins Harper, namorada de longa data de Evans, lembra como ele cruzava ou "derivava" de uma música para outra (PETTINGER, 1998, p.68), o que justifica esta fluidez e interpolação. A improvisação de Evans em Flamenco sketches, com seus arpejos sincopados ondulantes em Sol levando a trechos mais intricados, também faz referências a Peace piece, na qual este mesmo procedimento sinaliza arrefecimento.

\section{4 - Estudo de caso N.2: Peace piece}

No segundo estudo de caso: Chopin, Messiaen e Peace piece de Evans, demonstro uma relação fonte-produto mais aguda em relação a CHOPIN (s.d.) e um paralelo com potencial de interseção em relação a MESSIAEN (1964). PETTINGER (1998, p.69) identifica a Berceuse Op. 57 em Ré $b$ maior de Chopin, composta por volta de 1844, tanto como "a peça para piano que Evans conhecia bem" quanto uma "clara precursora" de Peace piece, faixa do disco Everybody digs Bill Evans (EVANS, 1958). Ele também questiona: "sabemos que [Evans] era um entusiasta de Scriabin, mas será que sabia que o Catálogo dos pássaros [1956-1958] de Olivier Messiaen acabava de aparecer?" (PETIINGER , 1998, p.69). Embora o biógrafo de Evans simplesmente responda que isso "não interessa", quero considerar essa pergunta e examinar os materiais e suas relações para chegar a algumas conclusões.

A Berceuse de Chopin é baseada em "um ostinato de dois acordes na mão esquerda o qual, assim com em Peace piece, não varia até chegar a uma cadência final" (PETTINGER , 1998, p.69). Embora Pettinger esteja correto, há alterações sutis na segunda metade de cada compasso dignas de nota. E Evans também cria pequenas mudanças. 0 efeito da melodia sobre o baixo é criar novas inflexões harmônicas, como a superposição expressiva das notas Lá $b$ - Lá natural sobre a nota Sol: Evans enfatiza a função dominante com 9a (Sol - Si Ré - Fá - Lá b /Lá natural). Outra similaridade: ambos Chopin e Evans introduzem suas melodias depois de várias ocorrências do ostinato (podemos até ir além e propor uma referência, uma triangulação: enquanto que a peça de Evans é definitivamente em 4/4, o efeito do padrão de mão esquerda seguido pela cantilena lenta e expressiva inevitavelmente nos leva a uma associação com o início do movimento ternário e lento do Concerto para piano em Sol de Ravel.

Para (PETTINGER, 1998, p.69), na Berceuse, "a linha da mão esquerda começa com simplicidade e, a cada dois ou quatro compassos, introduz uma ideia ornamental nova." Mas ele não menciona que a peça de Chopin é um tema com variações. Evans também lança mão de variações com frequência, geralmente trabalhando com "respirações" de dois compassos, agrupadas como seções 
de oito compassos. De fato, o ostinato à parte, Evans alegava que sua peça tinha "uma forma completamente livre" (PETINGER, 1998, p.69). Um gesto melódico realmente semelhante diz respeito aos vários Lás bemóis precedidos de ornamentos superiores de oitava nos c.1518 da Berceuse de Chopin e os vários Sóis precedidos pelos ornamentos superiores de sétima maior (Fá \# - Sol), a 11 compassos do final da Peace piece de Evans (AIKIN, 1980, p.49). A versão da sétima maior de Evans - Fá \#, Sol - poderia ser percebida como um erro de leitura gritante ou, no sentido bloominiano (BLOOM, 1973), reescrevendo a história (podemos ouvir uma correspondência ainda com o Mov. II das Valses nobles, mencionada acima: a linha superior de Ravel a partir do c.25 apresenta notas Dó reiteradas, precedidas por apojaturas de mesma nota).

Apesar de pequenas diferenças, a dimensão da paridade se aplica aqui: (1) o andamento; (2) a sensação de calma; (3) o ostinato harmônico básico I - V; (4) o emprego de variações; (5) o registro agudo do piano; (6) as escalas; (7) os arpejos; (8) os trinados; (9) a aumentação rítmica na coda; e (10) o diminuendo no final. Tudo isso significa que, ao invés da canção de ninar de Chopin ser apenas um "precursor", poderíamos considerá-la como um modelo conceitual e formal para Evans. Em outras palavras, há mais constância do que transformação, embora em um contexto inteiramente novo. Da mesma forma, a observação pertinente de que "em performance. . . [a Berceuse] deveria soar como uma improvisação escrita" (PETTINGER, 1998, p.69), nos autoriza a dar um outro passo: enquanto que Evans tem um ganho a partir de Chopin, podemos observar que, na direção oposta, além do seu status convencional de compositor, Chopin também era um improvisador. Suas variações virtuosísticas habitam o reino entre a composição e a performance quase espontânea.

Em uma segunda camada, relacionando Peace piece ao Catálogo dos pássaros de Messiaen, PETTINGER (1998, p.69), percebe "muitos cantos de pássaros incorporados ao ápice do arco de Evans, no qual a textura bitonal cintila à maneira do mestre francês". Esta é uma avaliação honesta, mas seria muita ingenuidade forçar o argumento de uma influência direta. Estritamente falando, a improvisação de Evans é bimodal e, ocasionalmente, polimodal: enquanto o baixo está em Dó (obedecendo, assim, aos próprios princípios tonais de Evans, mencionados anteriormente), a melodia invoca um modalismo muito mais ampliado e fluido. Podemos identificar os modos Jônico, Lídio, de tons inteiros, cromático, além de um modalismo com inflexão do blues, a exemplo das inflexões Mi/Ré \# e Lá \# /Si que ocorrem nos c.14-17 antes do final (AIKIN, 1980, p.49, c.60-65). Do meio da peça para frente, a paleta de dissonâncias de Evans torna-se mais picante do que é normal ao seu estilo. Entretanto, as texturas cristalinas em meio aos sons de sinos em forma de cascata (que alguém poderia chamar informalmente de efeitos "impressionistas"), os trinados e as notas ornamentais em destaque à maneira de Chopin são muito relevantes.
Podemos encontrar, em Evans, traduções equivalentes das notas repetidas ornamentadas do Catálogo dos pássaros (MESSIAEN, 1964). Na primeira peça, chamada Le chocard des alpes [Gralha alpina], por exemplo, o c.1 na p.4 diz respeito às sextinas de fusas reiteradas ao redor de Lá $b$ - Ré - Lá natural. Mais ainda, podemos traçar um paralelo entre o andamento relaxado da segunda peça de Messiaen - Le loriot [Papa-figos] - e Peace piece, e o mesmo com as alternâncias entre explosões melódicas e notas sustentadas, os contrastes de dinâmicas (a alternância de andamentos e as caracterizações [dos pássaros] que estão presentes também na oitava peça de Messiaen L'alouette calandrelle [Cotovia de dedos curtos]. Assim como Evans, Messiaen gostava do registro agudo extremo: na evocação ornamentada de Le Loriot ele utiliza trinados (c.1 na p.2). Por outro lado, o melro da canção canta, para o ouvinte, sétimas maiores e nonas menores, como Si $b$ - Lá; e Mi $b$ - Mi natural (p.3, c.4-10), ambos os intervalos comparáveis aos intervalos da improvisação de Evans, como Mi $b$ - Mi natural; Ré \# - Ré natural; e Fá \# - Sol (AIKIN, 1980, p.49). Messiaen emprega $5^{\text {as }}$ sem as terças no baixo do começo ao fim em Le loriot, ao passo que a peça de Evans termina exatamente desta maneira (veja descrição abaixo). Além disso, a terceira peça Le merle bleu [Melro azul], apresenta um Très lent com a seguinte designação "souvenir du merle bleu" (p. 24, c. 11), que compartilha da mesma atmosfera de amplidão da coda e das harmonias quartais de Peace Piece.

Claro que há diferenças bastante salientes, em relação às quais não cabe um julgamento de valor. Ao contrário, cada criador tem sua individualidade. As próprias obras existem em escalas bastante diferentes: se uma é uma grande coleção de muitos volumes, a outra é um exemplar único de uma miniatura improvisada (ou talvez duas do tipo), que dura apenas 6'43". As texturas de Messiaen são mais movimentadas e mais complexas do que as de Evans. Evans preserva um sentido mais forte de melodia acompanhada, uma prática que é, ironicamente, mais típica do Classicismo. Finalmente, há uma literalidade no Catálogo dos pássaros que é específico - quase científico - do pássaro que está sendo evocado. Por contraste, a concepção de Evans é muito mais livre e, nesse sentido, mais imaginativa.

De fato, na sua dimensão espiritual interna e mais ampla, há uma afinidade de Evans com a abordagem de um compatriota de Messiaen: André Jolivet, cuja modernidade de sua La princesse de Bali, (JOLIVET, 2002; uma das cinco peças para piano de Mana, de 1935), conclui com um gesto de ampliação harmônico-espacial (c.34-35) notavelmente similar àquele dos últimos quatro compassos de Peace piece (AIKIN, 1980, p.49). Os trechos de ambas as peças equilibram o gesto arpejado que desce do registro do soprano ao registro do baixo com um gesto ascendente que traz sonoridades de sinos, que reverberam até terminar em uma pausa. No compasso final da partitura, Jolivet marcou "comme un gong très grave", cuja sequência de notas muito graves Si $b$, Sol, 
Dó \#, Sol \# e Ré \# vão desaparecendo. Os dois últimos compassos de Evans cria um efeito semelhante, mas com ênfase em de intervalos de $4^{\text {as: }}$ : Sol - Dó - Fá; depois Lá Dó - Mi; depois Lá - Ré - Sol, antes do fragmento final baseado em $5^{\text {as }}$ : Dó - Sol - [Ré].

\section{5 - Conclusão}

Não há dúvidas sobre a relevância da música francesa para Evans, cuja força é comparável também à música russa para ele. Isto fica evidente não apenas em dados da literatura biográfica, confirmados pelos pontos de vista do próprio Evans, mas que também se somam às observações de sua prática, as quais procurei mostrar na breve análise deste texto. Ao investigar o papel desta música francesa na arte do improviso de Bill Evans, procurei enfaticamente não me adentrar em nenhum tipo de competição; as palavras de Gene LEES (1997, p.441) são de uma advertência salutar: "Em jazz. . . você escuta a expressão do indivíduo". Mas, embora respeitemos a individualidade, nenhum de nós existe em um vácuo cultural, pois o indivíduo é parcialmente definido como referência ao "outro". Concluo que a investigação de cruzamentos culturais e de gênero entre a música francesa e a música de Evans nos revela uma rica rede de influências que, nesses estudos de caso, destaco Ravel, Chopin, Messiaen e Jolivet. É interessante notar, nesses pelo menos, que há menos evidências do impressionismo que o próprio Evans aludiu, embora efeitos de um impressionismo, no sentido mais informal, sejam evidentes. Alguns exemplos de paralelismo, com pontos de interseção hermenêuticos, foram apresentados. Não obstante a problemática de estabelecer causalidade, outros exemplos específicos nos quais há fundamentação documentária suficiente podem ser considerados como respostas ecléticas do tipo fonte-produto, envolvendo a transformação de materiais musicais.

Passivel de discussão, a conexão entre o Concerto para a mão esquerda de Ravel e o All blues de Miles Davis/ Bill Evans (Estudo de caso N.1) envolve um efeito fonte-produto duplo uma vez que, em primeiro lugar, a figura inicial do primeiro provavelmente emergiu dos primórdios do jazz. Peace piece (Estudo de caso N.2) avança esta ideia com uma engenhosa triangulação: Evans, Chopin e Bernstein - à qual acrescentamos Messiaen e Jolivet - com algumas relações bem claras, ou fechadas; outras mais ambíguas, ou abertas. Por exemplo, embora a composição do Catálogo de pássaros seja absolutamente contemporânea à criação de Peace piece, o som do canto de pássaro já estava aparente em algumas das músicas anteriores de Messiaen, às quais Evans pode ter sido exposto (embora seja improvável que encontremos uma evidência concreta para fundamentar ou refutar esta possibilidade).

Metodologicamente, a abordagem flexível advogada por RAVEL (1928, p.140) em Contemporary Music se mostrou aplicável ao ecletismo de Evans. Os pontos que realmente tem uma fonte identificável fazem parte da "adoção" e "estilização", refletindo graus diversos da transformação coloristica de Ravel dentro de novos contextos artísticos. Mas, como lembra Chuck ISRAELS ${ }^{1}$ (1985, p.110-111), o estilo de Evans nunca soa artificial ou construído: "as ideias eram filtradas por ele e emergiam com profunda convicção. . . tudo era sintetizado em um estilo integrado". Enquanto que o raciocínio de BLOOM (1973), que está centrado na ideia de uma leitura errônea da história, tem sido considerado de pouca e limitada (hermeneuticamente falando) aplicabilidade, defendo que a abordagem geral de Evans é, notoriamente, como um "abraço de inclusão" da história cultural, mais generoso, como advogado por ELIOT (1951) em Tradition and the individual talent.

Assim, o repertório musical francês se revelou como um importante catalisador modal e textural, especialmente nos momentos mais introvertidos de Evans, como em Peace piece. Além do que mostram os estudos de caso de 19581959, pode-se dizer que o interesse duradouro de Evans pela música francesa é comprovado por suas últimas gravações embora, enquanto atividade comercial, seus arranjos da música de Fauré e Chopin para trio de jazz e orquestra (EVANS, 1965) caminhem em outra direção. Essa associação com os eruditos franceses melhorou o status de Evans na Europa - para não dizer também nos Estados Unidos, onde ele tinha de lutar tanto com o fato de ser branco e, não raro, de ser considerado afeminado - expandindo potencialmente sua penetração no velho continente. Nesse sentido, testemunham, por exemplo, as belas e curiosamente literais performances de suas improvisações, incluindo Peace piece, gravada pelo renomado pianista francês Jean-Yves THIBAUDET (1997). Finalmente, é intrigante que uma antiga música francesa tenha sobrevivido e se reconfigurado - à maneira do camaleão - dentro de um novo contexto do jazz modal do pós-guerra. 


\section{Referências}

BERLINER, P. F. Picking notes out of thin air? In: Thinking in jazz: the infinite art of improvisation (Org. P. F. Berliner). Chicago: University of Chicago Press, 1994, p.1-17.

BLOOM, H. The Anxiety of influence: A Theory of poetry. Nova lorque: Oxford University Press, 1973.

DAVIS, M.; TROUPE, Q. Miles: the autobiography. Londres: Macmillan, 1989.

ELIOT, T. S. Tradition and the individual talent [1919]. In: Selected essays. Londres: Faber, 1951, p.13-22.

ENSTICE, W.; RUBIN, P. Jazz spoken here. Baton Rouge: Louisiana State University Press, 1992.

GINIBRE, J. L. Il parle, le trio dont on parle. Jazz Magazine, 1965, n.116, p.28-33.

Bill Evans: Time remembered. Jazz Times, 1997, v.27, n.1, p.32-35, 38, 144-145 (Republicação traduzida da entrevista de 1965).

HODEIR, A. Jazz: its evolution and essence. Londres: Jazz Book Club, 1958.

ISRAELS, C. Bill Evans (1929-80): A musical memoir. Musical Quarterly, 1985, v.71, n.2, p. 109-115.

LEES, G. The poet: Bill Evans. In: Reading jazz: a gathering of autobiography, reportage, and criticism from 1919 to now (Ed. R. Gottlieb). Londres: Bloomsbury, 1997, p.419-444.

MAWER, D. Musical objects and machines. In: The Cambridge companion to Ravel(Ed. D. Mawer). Cambridge: Cambridge University Press, 2000, p. 47-67.

PETTINGER, P. Bill Evans: how my heart sings. New Haven: Yale University Press, 1988.

RAVEL, M. Contemporary music. Rice Institute Pamphlet, 1928, v.15, n.2, p.131-145.

STRAUS. J. N. Remaking the past: musical modernism and the influence of the tonal tradition. Cambridge: Harvard University Press, 1990.

\section{Partituras e transcrições}

AIKIN, J. Bill Evans: Peace Piece(Transcription). (Contemporary) Keyboard Magazine, 1980, v.6, n.6, p.46-49.

CHOPIN, F. Berceuse Op. 57. In: Chopin album. Londres: Bosworth Edition, s.d.

DAVIS, M. Kind of blue. Partituras transcritas por R. Du Boff, M. Vinci, M. Davis e J. Davis. Milwaukee: Hal-Leonard, s.d. [c. 2000].

EVANS, Bill. Peace Piece de Bill Evans. Transcrição de Jim Aikin. Per Musi. v.28. Belo Horizonte: UFMG, 2013. p.15-20.

JOLIVET, A. La princesse de Bali. In: Mana. Paris: Editions Jobert, 2002.

MESSIAEN, O. Catalogue d'oiseaux. Paris: Editions Alphonse Leduc, 1964.

MILHAUD, D. La création du monde. Paris: Editions Max Eschig, 1923.

RAVEL, M. Valses nobles et sentimentales. Paris: Editions Durand, 1911.

Sonate pour violon et piano. Paris: Editions Durand, 1927.

Concerto pour la main gauche. Paris: Editions Durand, 1931.

Concerto pour piano et orchestre. Paris: Editions Durand, 1932.

\section{Gravações}

DAVIS, M. Kind of blue. (CD CK 64935). Columbia, 1959.

EVANS, B. Peace piece. In: Everybody digs Bill Evans (CD Riverside 291). Riverside, 1958.

. Pavane, Blue interlude. In: Bill Evans Trio with Symphony Orchestra (CD V6 8640). Verve, 1965.

THIBAUDET, J. Y. Conversations with Bill Evans(CD B0000042H1). Decca, 1997.

\section{Bibliografia adicional}

BRUBECK, D. 1959: The beginning of beyond. In: The Cambridge companion to jazz (Eds. M. Cooke e D. Horn). Cambridge: Cambridge University Press, 2002, p.177-201.

GRIDLEY, M. Jazz styles: history and analysis. 4ª ed. Englewood Cliffs: Prentice Hall, 1994.

KAHN, A. Kind of Blue: the making of the Miles Davis masterpiece. Londres: Granta Books, 2000.

KERNFELD, B. Improvisation. In: What to Listen for in Jazz. New Haven: Yale University Press, 1995, p.119-158.

. Miles (Dewey, III), Davis. In: The New Grove dictionary of jazz. 2a ed. (Ed. B. Kernfeld). Nova lorque: Oxford University

Press, 2002, v.1, p.573-577.

LEES, G. Meet me at Jim and Andy's: jazz musicians and their world. Oxford: Oxford University Press, 1988.

MURRAY, E.; KERNFELD, B. Bill Evans (ii). In: The New Grove dictionary of jazz. $2^{\text {a }}$ ed. (Ed. B. Kernfeld). Nova lorque: Oxford

University Press, 2002, v.1, p.723- 726.

SHADWICK, K. Jazz: legends of style. Londres: Quintet Publishing, 1998.

SHIPTON, A. A New history of jazz. Londres: Continuum, 2002. 


\section{Transcrições adicionais}

MEHEGAN, J. Contemporary piano styles: Jazz Improvisation IV. New York: Watson- Guptill Publications/Simon and Schuster, 1965.

OLSEN, D. C.; ROED, T. (Eds.). The Artistry of Bill Evans. Transcrições de P. Wetzel, apresentação de C. Blancq. Miami: CPP/ Belwin/Warner Bros. Publications, 1989.

\section{Gravações adicionais}

EVANS, B. New jazz conceptions (CD Riverside 223). Riverside, 1956. Peri's Scope. In: Portrait in Jazz (CD Riverside 1162). Riverside, 1959.

RUSSELL, G. The Jazz workshop (CD LPM 2534). RCA Victor, 1956.

\section{Website}

EVANS, B. www.billevanswebpages.com

\section{Nota}

1 Charles H. "Chuck" Israels (nascido em 1936) foi o contrabaixista de Bill Evans no período de 1961 a 1966. Também compositor e arranjador, é também conhecido por seu trabalho pioneiro como Diretor do National Jazz Ensemble de 1973 a 1981.

Deborah Mawer, Professora Senior da Universidade de Lancaster, Inglaterra, e há muito tempo interessada nas interações entre a música francesa e os primórdios do jazz e blues, publicou quatro livros sobre a música francesa do século XX. Seu livro Darius Milhaud: Modality and Structure in Music of the 1920s (1997) apresenta um estudo de caso sobre o balé inspirado no jazz, La Création du monde. Já o livro Ravel Studies (2010) inclui o capítulo Crossing Borders: Ravel's Theory and Practice of Jazz. 0 artigo "Parisomania? Jack Hylton and the French Connection" foi publicado no Journal of the Royal Musical Association (2008), enquanto que "Jazzing a Classic: Hylton and Stravinsky's Mavra at the Paris Opéra" foi publicado no periódico Twentieth-Century Music (2009). No seu projeto atual, French Music in Conversation with Jazz, discute duas interações entre a música erudita e o jazz: primeiro, a música francesa do entre-guerras e os primórdios do jazz; segundo, o impacto da música francesa no jazz modal da década de 1950. 0 presente artigo, publicado em Per Musi é um texto em processo sobre o segundo tema. Publicou também os livros The Cambridge Companion to Ravel (2000) e The Ballets of Maurice Ravel: Creation and Interpretation (2006). Entre os periódicos que publicaram seus artigos estão o Journal of the Royal Musical Association, Twentieth-Century Music, Music and Letters, Journal of Music Theory, Music Theory Online, Opera Quarterly, French History e o British Journal of Music Education.

Fausto Borém é Professor Titular da UFMG, onde criou o Mestrado e a Revista Per Musi. Pesquisador do CNPq desde 1994, publicou dois livros, três capitulos de livro, dezenas de artigos sobre práticas de performance e suas interfaces (composição, análise, musicologia, etnomusicologia da música popular e educação musical) em periódicos nacionais e internacionais, dezenas de edições de partituras e recitais nos principais eventos nacionais e internacionais de contrabaixo. Recebeu diversos prêmios no Brasil e no exterior como solista, teórico, compositor e professor. 